\title{
Role of mineralization inhibitors in the regulation of hard tissue biomineralization: relevance to initial enamel formation and maturation
}

\author{
Henry C. Margolis ${ }^{1,2 *}$, Seo-Young Kwak ${ }^{1,2}$ and Hajime Yamazaki ${ }^{1,2}$ \\ 1 Department of Applied Oral Sciences, Center for Biomineralization, The Forsyth Institute, Cambridge, MA, USA \\ 2 Department of Developmental Biology, Harvard School of Dental Medicine, Boston, MA, USA
}

Edited by:

Bernhard Ganss, University of

Toronto, Canada

\section{Reviewed by:}

Yuji Mishina, University of Michigan, USA

Peter Proff, Regensburg University, Germany

\section{*Correspondence}

Henry C. Margolis, Department of Applied Oral Sciences, Center for Biomineralization, The Forsyth Institute, 245 First Street, Cambridge, MA 02142, USA e-mail: hmargolis@forsyth.org

\begin{abstract}
Vertebrate mineralized tissues, i.e., enamel, dentin, cementum, and bone, have unique hierarchical structures and chemical compositions. Although these tissues are similarly comprised of a crystalline calcium apatite mineral phase and a protein component, they differ with respect to crystal size and shape, level and distribution of trace mineral ions, the nature of the proteins present, and their relative proportions of mineral and protein components. Despite apparent differences, mineralized tissues are similarly derived by highly concerted extracellular processes involving matrix proteins, proteases, and mineral ion fluxes that collectively regulate the nucleation, growth and organization of forming mineral crystals. Nature, however, provides multiple ways to control the onset, rate, location, and organization of mineral deposits in developing mineralized tissues. Although our knowledge is quite limited in some of these areas, recent evidence suggests that hard tissue formation is, in part, controlled through the regulation of specific molecules that inhibit the mineralization process. This paper addresses the role of mineralization inhibitors in the regulation of biological mineralization with emphasis on the relevance of current findings to the process of amelogenesis. Mineralization inhibitors can also serve to maintain driving forces for calcium phosphate precipitation and prevent unwanted mineralization. Recent evidence shows that native phosphorylated amelogenins have the capacity to prevent mineralization through the stabilization of an amorphous calcium phosphate precursor phase, as observed in vitro and in developing teeth. Based on present findings, the authors propose that the transformation of initially formed amorphous mineral deposits to enamel crystals is an active process associated with the enzymatic processing of amelogenins. Such processing may serve to control both initial enamel crystal formation and subsequent maturation.
\end{abstract}

Keywords: amorphous calcium phosphate, biomineralization, dental enamel, inhibitors, mineral phase transformation

\section{INTRODUCTION}

Biomineralization is the process by a wide variety of living organisms, including mollusks, sponges and unicellular diatoms, for example, produce functional mineralized tissues (Mann, 2001). Vertebrate mineralized tissues, like dental enamel, dentin, cementum, and bone, fulfill specialized functions that reflect differences in their hierarchical organization and composition (Weiner, 1986). Although each of these tissues is comprised of a crystalline calcium apatite mineral phase and a protein component, they differ with respect to overall structure, crystal size and shape, level and distribution of trace mineral ions, the nature of the proteins present, and the relative proportions of mineral and protein components. Differences in structural organization and composition give rise to mineralized tissues with different physical and mechanical properties that are well-suited for their intended biological purpose (Birchall, 1989; Currey, 1999).

Although the mechanisms by which these mineralized tissues form are not fully understood, it is apparent that the unique structure of each mineralized tissue, including dental enamel, is the result of highly concerted cell and extracellular processes that regulate the on-set, growth rate, shape, location and arrangement of forming mineral crystals (Weiner, 1986). Evidence also suggests that critical aspects of hard tissue formation are controlled, in part, through the regulation of specific molecules that inhibit mineralization. This paper addresses the role of mineralization inhibitors in the regulation of biological mineralization and the potential relevance of such mechanisms in the process of dental enamel formation (amelogenesis).

\section{FUNDAMENTAL ASPECTS OF VERTEBRATE MINERALIZED TISSUE FORMATION}

\section{EXTRACELLULAR PROTEIN MATRIX AND MINERALIZED TISSUE COMPOSITION}

Biominerals are formed utilizing similar fundamental strategies, although there are unique differences that distinguish one tissue from another, especially dental enamel. Enamel, dentin and bone 
are each derived from specialized cells; ameloblasts, odontoblasts and osteoblasts, respectively. These cells secrete an extracellular protein matrix that is predominantly comprised of a hydrophobic protein and smaller amounts of acidic hydrophilic molecules. In bone and dentin, the matrix is mostly collagen, while the major enamel matrix component ( $>90 \%$ ) is amelogenin. It has been proposed that biomineralization is generally regulated through interactions between hydrophobic components, which provide a skeletal or space-filling structure (e.g., collagen in bone and dentin), and hydrophilic (acidic) molecules (e.g., phosphophoryn in dentin Veis et al., 1991; He et al., 2005) that regulate crystal nucleation and growth (Weiner, 1986; Addadi and Weiner, 1992). Considerable evidence shows that a highly-ordered preassembled collagen matrix serves as a template to guide subsequent mineralization, as we have previously discussed (Margolis et al., 2006). The initial collagenous matrix is mineral free and undergoes a series changes in structure and composition prior to mineralization (Weinstock and Leblond, 1973; Septier et al., 1998; Beniash et al., 2000), resulting in the formation of tissues that are $40-50 \%$ mineral and $\sim 35 \%$ organic by volume (Nikiforuk, 1985). The protein matrix of forming enamel is similarly comprised of a predominant hydrophobic protein (amelogenin) and two key minor protein components enamelin (hydrophilic and acidic) and ameloblastin (amphiphilic and acidic). The observations that the amelogenin-null mouse (Gibson et al., 2001) exhibits a marked enamel phenotype and that enamel does not form in the absence of enamelin (Hu et al., 2008; Smith et al., 2009) or ameloblastin (Fukumoto et al., 2004; Smith et al., 2009; Wazen et al., 2009) are in agreement with the proposed general requirement for hydrophobic-hydrophilic molecular interactions in biomineral formation.

Despite similarities in the hydrophobic/hydrophilic composition of developing extracellular bone, dentine and enamel matrices that lead to the formation of a similar mineral phase (i.e., a carbonated hydroxyapatite), mature enamel and the mechanism of its formation differ from those of dentine and bone. First, long thin ribbons of enamel mineral begin to form almost immediately after ameloblasts lay down the enamel matrix (Nylen et al., 1963; Arsenault and Robinson, 1989; Smith, 1998), indicating that mineralization does not take place within a pre-assembled enamel matrix template, as in the case of collagen-based tissues. These long thin mineral ribbons extend hundred of microns to the full thickness of the enamel layer that is laid down during the secretory stage of amelogenesis, although the mineral component occupies only $10-20 \%$ of the enamel volume, with the remaining volume occupied by the enamel matrix and water (Robinson et al., 1988; Fukae, 2002). During the maturation stage of amelogenesis (Robinson and Kirkham, 1985), the extracellular enamel matrix is almost completely removed by resident proteases and the initially formed mineral ribbons grow in width and thickness to form a dense mineralized tissue that is $>95 \%$ mineral by weight, with only $1-2$ weight $\%$ of remaining protein and a small amount of water. Hence, there is an inverse relationship between the protein and mineral content during enamel development (Robinson et al., 1979), as illustrated in Figure 1. Unlike that seen in bone and dentin, the enamel matrix is transient and the resulting enamel tissue is almost fully mineralized. The transient nature

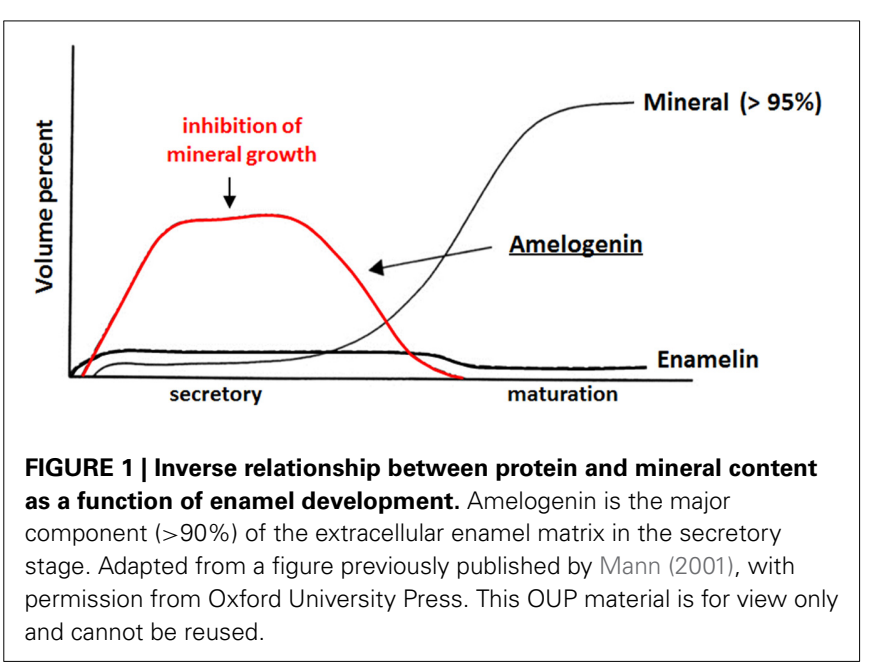

of the enamel matrix is uncommon in biomineralization (Weiner, 1986).

\section{CALCIUM PHOSPHATE FORMATION IN VITRO AND IN VIVO}

The formation of a calcium phosphate mineral phase in vitro and in vivo requires a condition of supersaturation with respect to the forming phase. As shown in Equation 1 for hydroxyapatite (HA: $\left.\mathrm{Ca}_{5} \mathrm{OH}\left(\mathrm{PO}_{4}\right)_{3}\right)$, a prototype for enamel, dentin and bone mineral, the degree of supersaturation (DS) can be defined as the ratio of the mean ionic activity product for a given mineral phase in solution to its thermodynamic solubility product constant (e.g., $\left.\mathrm{K}_{\mathrm{SP}-\mathrm{HA}}\right)$ defined in the same manner, where "()" represent the activity of the enclosed ion [e.g., $\left.\left(\mathrm{Ca}_{f}^{2+}\right)\right]$. The activity of an ion in solution is equal to the product of the concentration of the ion $\left(\left[\mathrm{x}_{\mathrm{i}}^{\mathrm{Z}}\right]\right)$ and an ion activity coefficient $\left(\mathrm{a}_{\mathrm{i}}\right)$ that is a function of the ion size, charge, ionic strength and temperature. Such quantities can be calculated using ion-speciation software, as we have previously described (Moreno and Margolis, 1988). Supersaturation with respect to other calcium phosphate phases, such as octacalcium phosphate [OCP: $\mathrm{Ca}_{4} \mathrm{H}\left(\mathrm{PO}_{4}\right)_{3}$ ] and dicalcium phosphate dihydrate (DCPD: $\mathrm{CaHPO}_{4} \cdot 2 \mathrm{H}_{2} \mathrm{O}$ ), can be defined similarly as indicated in Equations (2) and (3), respectively. A minimum requirement for mineral formation in vitro or in vivo is the condition of supersaturation. As indicated by Equations 1-3, DS is a function of calcium, phosphate and hydrogen ion activities.

$$
\begin{aligned}
\mathrm{DS}_{\mathrm{HA}} & =\left[\left(\mathrm{Ca}_{f}^{2+}\right)^{5}\left(\mathrm{OH}^{-}\right)\left(\mathrm{PO}_{4}^{3-}\right)^{3}\right]^{1 / 9} / \mathrm{K}_{\mathrm{SP}-\mathrm{HA}} \\
\mathrm{DS}_{\mathrm{OCP}} & =\left[\left(\mathrm{Ca}_{f}^{2+}\right)^{4}\left(\mathrm{H}^{+}\right)\left(\mathrm{PO}_{4}^{3-}\right)^{3}\right]^{1 / 8} / \mathrm{K}_{\mathrm{SP}-\mathrm{OCP}} \\
\mathrm{DS}_{\mathrm{DCPD}} & =\left[\left(\mathrm{Ca}_{f}^{2+}\right)\left(\mathrm{HPO}_{4}^{2-}\right)\right]^{1 / 2} / \mathrm{K}_{\mathrm{SP}-\mathrm{DCPD}}
\end{aligned}
$$

where, $\left(\mathrm{X}_{i}^{z}\right)=\mathrm{a}_{i} \times\left[\mathrm{X}_{i}^{z}\right]$ and $\mathrm{Ca}_{f}^{2+}$ is free calcium.

Regarding the mineralization process, a given solution can be supersaturated with respect to more than one calcium phosphate phase at the same time. Due, in part, to kinetic factors 
(for review, see Mann, 2001), however, the more soluble phase will form first and, through a series of phase transformations, convert to HA, which is the most thermodynamically stable calcium phosphate phase of the group. This phenomenon, called the Ostwald-Lussac law of stages, occurs in nature, as it does in vitro (Eanes, 2001). For example, it has been shown (Schroeder, 1969) that DCPD and OCP are the first mineral phases seen in forming dental calculus that subsequently convert to HA over time. Consistent with this observation and Ostwald-Lussac law of stages, at physiological $\mathrm{pH}(\mathrm{pH} 7)$ and ionic strength (163 mM), HA has a relatively low solubility (expressed as the concentration of dissolved $\left.\mathrm{Ca}^{2+}\right)$ of $0.11 \mathrm{mM}$, in comparison to OCP $(1.42 \mathrm{mM})$ and DCPD (2.09 mM), as calculated (Moreno and Margolis, 1988). Such transformations may go through multiple phases before reaching the stable $\mathrm{HA}$ phase, depending on the free energy of activation $(\Delta G)$ associated with nucleation $(n)$, growth $(g)$, and phase transformation $(\mathrm{t})$, as previously discussed and illustrated in Figure 2 (Colfen and Mann, 2003).

Based on the discussion above, the role of precursor phases involved in HA and biomineral formation has received considerable attention. The calcium phosphate mineral phases discussed so far are crystalline in nature, as confirmed using spectroscopic (FT-IR, Raman) and diffraction (X-ray and electron diffraction) methods. However, it has been known for many years (for review, see Eanes, 2001) that amorphous calcium phosphate (ACP) is the first mineral phase to form upon mixing sufficiently high concentrations of calcium and phosphate. ACP is more soluble than the noted crystalline calcium phosphates and is the kinetically favored product (Meyer and Eanes, 1978), although it readily undergoes phase transformation to $\mathrm{HA}$, as shown in

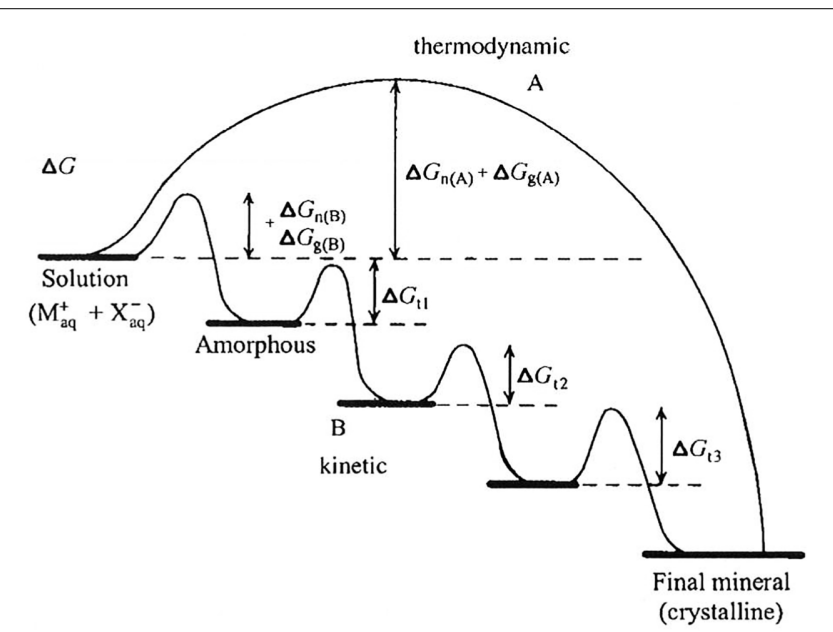

FIGURE 2 | Crystallization pathways under thermodynamic and kinetic control, illustrating that mineral formation may go through multiple phases (path $B$ ) before reaching the stable final crystalline product (e.g., HA), as discussed in the text, depending on the free energy of activation $(\Delta \mathrm{G})$ associated with nucleation $(\mathrm{n})$, growth $(\mathrm{g})$, and phase transformation (t). As shown, amorphous phases are frequently observed first under kinetically controlled conditions. This figure is from a publication (Colfen and Mann, 2003) in which this phenomenon is discussed in greater detail and is reproduced with permission. Copyright Wiley-VCH Verlag $\mathrm{GmbH} \&$ Co. KGaA.
Figure 3. The presence of ACP in vertebrate mineralized tissues (Posner and Betts, 1975) has been a topic of considerable debate (Termine and Posner, 1966; Boskey, 1997; Eanes, 2001; Weiner, 2006) because of its transient nature. However, recent evidence suggests that the transient nature of an amorphous mineral phase, that is, the formation of an amorphous mineral phase and its subsequent transformation to a crystalline solid, is a key element in biological mineral formation (Beniash et al., 1997; Weiner et al., 2005; Deshpande and Beniash, 2008; Kwak et al., 2009; Margolis and Beniash, 2010; WiedemannBidlack et al., 2011). More recently, the importance of sequential steps involving ACP formation and transformation has been confirmed in vitro (Habraken et al., 2013), showing that the existence of pre-nucleation clusters that precede ACP formation lowers the energy barrier to nucleation and makes amorphous phases "accessible" under conditions that would favor the formation of more stable crystalline phases. Hence, it appears calcium phosphate formation in vivo and in vitro similarly proceed through a sequence of phase transformations, potentially involving: $\mathrm{ACP} \rightarrow$ $\mathrm{DCPD} \rightarrow \mathrm{OCP} \rightarrow \mathrm{HA}$. As will be discussed below, however, matrix molecules can dramatically influence the phase transformation process.

\section{ROLE OF MINERALIZATION INHIBITORS IN BIOLOGICAL MINERALIZATION STABILIZATION OF SUPERSATURATION IN VIVO}

As illustrated in Figure 3, under conditions of relatively high supersaturation brought about by the rapid mixing of calcium and phosphate solutions, mineralization takes place spontaneously. This process involves the homogeneous nucleation and formation of precursor ACP nanoparticles, which subsequently transform to crystalline HA. In the absence of a buffer, this process causes a sharp decrease in $\mathrm{pH}$ due to the precipitation of a basic solid phase (Figure 4). In the presence of the full-length native amelogenin, P173, the solution $\mathrm{pH}$ does not drop and remains relatively constant for long periods of time, as illustrated in Figure 4, by preventing the bulk formation of HA crystals, as shown in Figure 5 (Wiedemann-Bidlack et al., 2011). As can be seen in this TEM micrograph, P173 has the capacity to stabilize initially formed nanoparticles of ACP and prevent transformation to crystalline HA, as seen in the control (Figure 3). Of note, truncated native amelogenin, P148 that lacks the hydrophilic Cterminus was similarly found to be a potent stabilizer of ACP (Kwak et al., 2009). Hence, P173 and P148 are inhibitors of spontaneous HA crystal formation. In doing so, the supersaturation status of the experimental solution is also maintained, along with its inherent stored capacity to promote mineralization. Notably, native amelogenins like P173 and P148 contain a single phosphorylated site (serine-16) within the $\mathrm{N}$-terminus (Margolis et al., 2006), as further discussed below.

The stabilization of biological fluids through the inhibition of HA crystal formation is well known and appears to fulfill biologically important functions. A prime example is human saliva that has been shown (Hay et al., 1982) to be supersaturated with respect to all known calcium phosphate phases. Evidence suggests that this condition of supersaturation is maintained by a family of salivary phosphoproteins, which have been shown to 


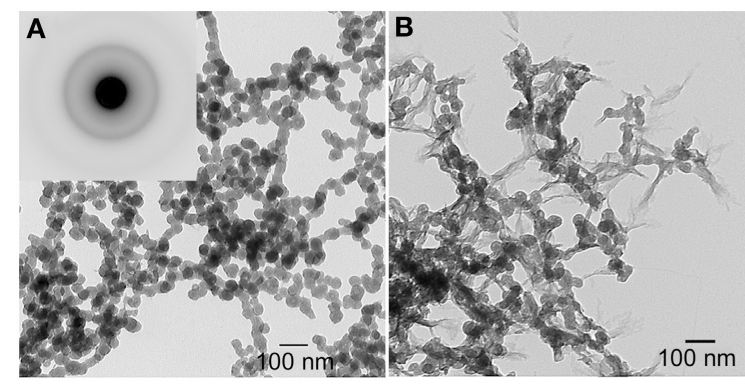

FIGURE 3 | TEM micrographs of calcium phosphate mineral products formed in the absence (control) of protein examined at selected times: $\mathbf{1 5} \mathrm{min}$ (A), $\mathbf{4 5} \mathrm{min}$ (B), 1-4 h (C), and $\mathbf{1 d}$ (D). As shown at $15 \mathrm{~min}$ (A), amorphous calcium phosphate (ACP) was initially formed based on the
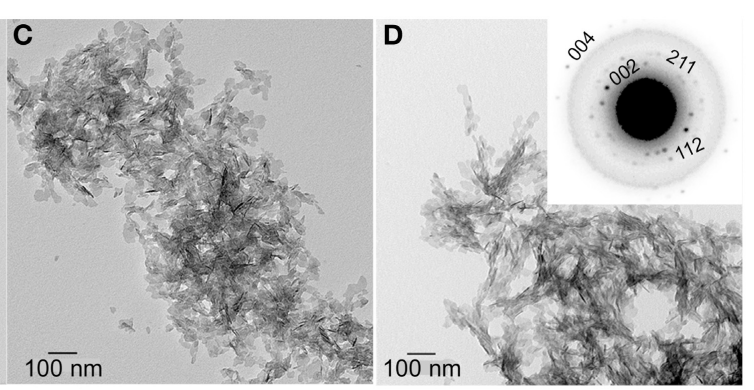

observed (inset) selected area electron diffraction (SAED) pattern. At $45 \mathrm{~min}$ ACP phase transformation could be seen. After $1-4 \mathrm{~h}$, randomly arranged plate-like apatitic crystals were found and confirmed by SAED analyses (D, inset). This image was reproduced from Kwak et al. (2009).

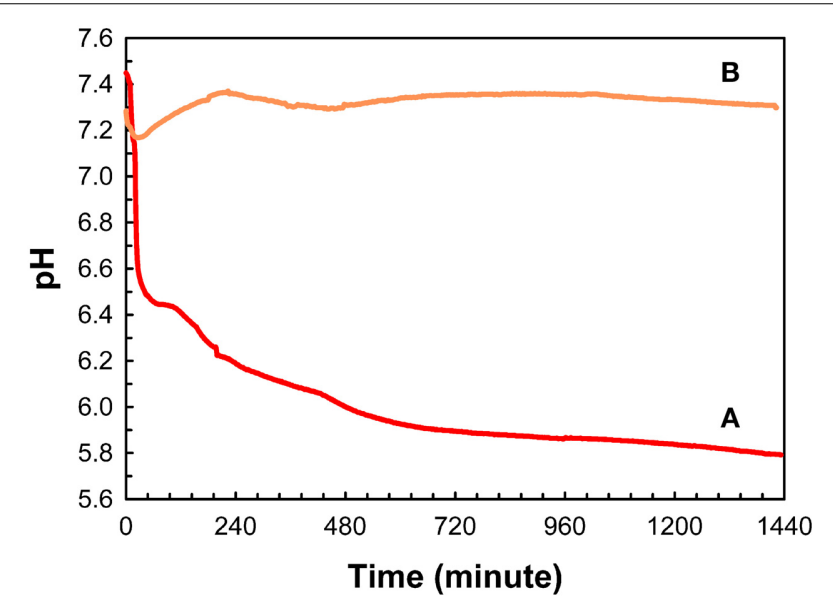

FIGURE 4 | Changes in $\mathrm{pH}$ as a function of time observed during mineralization experiments carried out in $60 \mu \mathrm{L}$ sample volumes, in the absence $(A)$ and presence of native full-length amelogenin, P173, at $2 \mathbf{~ m g} / \mathbf{m L}$ (B). This image was reproduced from Wiedemann-Bidlack et al. (2011).

be potent inhibitors of spontaneous calcium phosphate formation and seeded HA crystal growth in vitro (e.g., Hay et al., 1979). Under these conditions that persist in human saliva, calcium phosphate formation on hard and soft tissue surfaces in the oral cavity is prevented, as is the dissolution of tooth enamel in saliva. If saliva did not contain calcium and phosphate ions it would be undersaturated with respect to tooth enamel (i.e., with $\mathrm{DS}_{\mathrm{EN}}<1$ ) and potentially promote the dissolution of enamel surfaces, albeit at a very slow rate. In fact, the observed spontaneous reversal of untreated early carious lesions (Koulourides et al., 1965; Dirks, 1966), where incipient lesions (i.e., white spots) take up mineral ions to become sound surfaces, can be attributed to the condition of saliva supersaturation. Hence, the prevention of unwanted mineral deposits in the oral cavity and the capacity of saliva to promote the repair (remineralization) of beginning enamel lesions is due to resident inhibitors of calcium phosphate formation that maintain saliva in its supersaturated state. Similarly, inhibitors of calcium oxalate formation have been

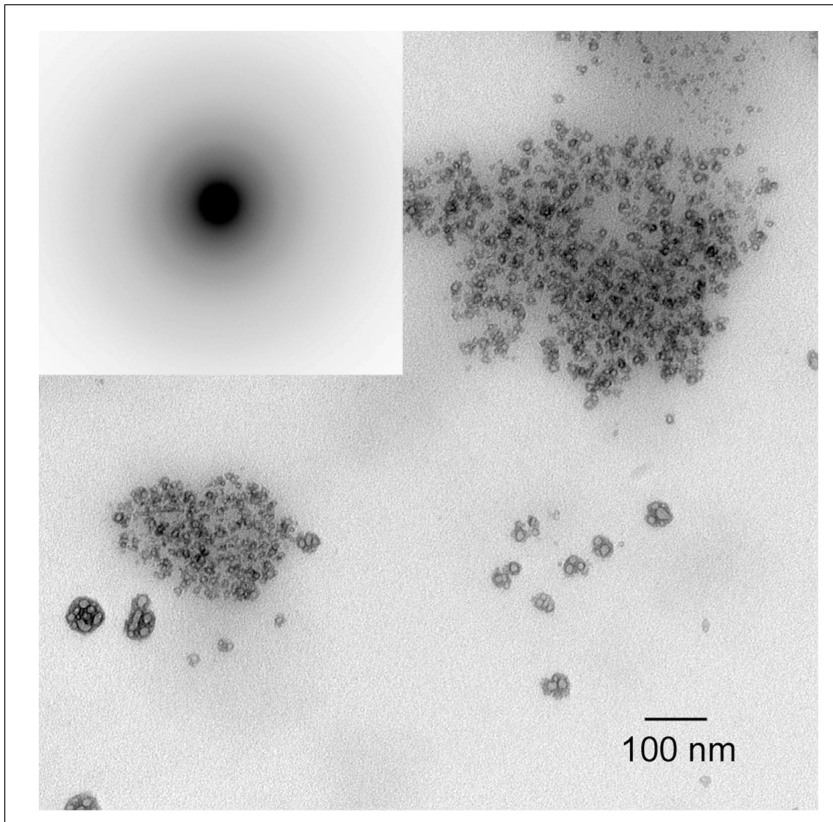

FIGURE 5 | TEM micrograph of calcium phosphate mineral products formed in the presence of native full-length amelogenin, P173, at $\mathbf{2} \mathbf{~} \mathbf{g} / \mathbf{m L}$. Only ACP was observed, even after $1 \mathrm{~d}$, as confirmed by selected area electron diffraction (inset). This image was reproduced from Wiedemann-Bidlack et al. (2011).

identified in urine and are believed to play an important role in preventing the formation of kidney stones (e.g., Nene et al., 2013). Finally, it has been shown that spontaneous calcification of arteries and cartilage takes place in mice that lack the mineral binding matrix GLA protein, a known mineralization inhibitor. These latter observations, lead the authors of that study to conclude that the calcification of the extracellular matrix is a ubiquitous process that must be actively inhibited in soft tissues that do not normally mineralize (Luo et al., 1997).

\section{REGULATION OF BIOMINERAL FORMATION}

Mann (2001) summation that "The chemical control of crystallization pathways that involve a sequence of kinetic inhibition and 
phase transformation can result in a high degree of selectivity in crystal structure and composition," is perhaps best illustrated in biology where numerous inhibitors of HA formation have been identified, including magnesium ion, carbonate, proteoglycans, polyphosphate and other phosphorylated molecules. In particular, inorganic pyrophosphate $\left(\mathrm{PP}_{\mathrm{i}}\right)$ has been long recognized as a potent inhibitor of mineralization and as a potential regulator of biological mineralization. At micro-molar levels, $\mathrm{PP}_{\mathrm{i}}$ inhibits the growth (Francis, 1969; Meyer and Nancollas, 1973; Meyer, 1984; Moreno et al., 1987) and dissolution (Fleisch et al., 1966; McGaughey and Stowell, 1977; McGaughey, 1983) of HA, as well as HA crystal formation from ACP (Termine et al., 1970; Robertson, 1973; Blumenthal et al., 1975). A study in our laboratory (Moreno et al., 1987) indicated that the inhibition of $\mathrm{HA}$ crystal growth results from $\mathrm{PP}_{\mathrm{i}}$ adsorption to discrete growth sites on HA surfaces, in the same fashion that has been proposed to explain the inhibition of crystal growth by macromolecules (Moreno et al., 1979). Stabilization of ACP may similarly involve $\mathrm{PP}_{\mathrm{i}}$ binding to ACP nanoparticles (Ofir et al., 2004).

Based on additional in vitro findings (Meyer, 1984) that suggest calcification cannot occur in vivo in the presence of physiological levels of $\mathrm{PP}_{\mathrm{i}}$, it was proposed (Meyer and Reddi, 1985) that pyrophosphatases regulate mineral deposition in bone and cartilage by hydrolyzing $\mathrm{PP}_{\mathrm{i}}$ (to two molecules of orthophosphate) to eliminate its inhibitory activity. This overall concept has been supported by the elucidation (Ho et al., 2000) of the role of progressive ankylosis (ank) gene that encodes a transmembrane protein that appears to regulate calcification (and arthritis) by controlling both intracellular and extracellular levels of $\mathrm{PP}_{\mathrm{i}}$. Additional evidence has also been obtained showing that tissue non-specific alkaline phosphatase (TNAP) and plasma cell membrane glycoprotein-1 (PC-1) are key enzyme regulators of the extracellular $\mathrm{PP}_{\mathrm{i}}$ concentrations required for controlled bone mineralization (Hessle et al., 2002). PC-1 is the major producer of the $\mathrm{PP}_{\mathrm{i}}$ inhibitor, while TNAP can regulate the promotion of the onset of bone mineralization by hydrolyzing $\mathrm{PP}_{\mathrm{i}}$. Consistent with this idea, it has been demonstrated in vitro that upon the removal of $\mathrm{PP}_{\mathrm{i}}$ from solution, either through adsorption or by HA surface-induced hydrolysis (Meyer, 1984; Litman and Margolis, unpublished findings), or by enzymatic degradation of $\mathrm{PP}_{\mathrm{i}}, \mathrm{PP}_{\mathrm{i}}$-stabilized calcium phosphate solutions rapidly form calcium phosphates.

With respect to amelogenesis, alkaline phosphatase (AP) has been found in secretory enamel, leading investigators to suggest that "dephosphorylation" of amelogenin (e.g., by AP) may play a role in regulating enamel formation (Brookes et al., 1998). Although this suggestion has not been fully substantiated in vivo, a study using cultured embryonic tooth germs showed that nonspecific inhibition of phosphorylation by casein kinase impaired enamel formation (Torres-Quintana et al., 2000), lending support to the idea that phosphorylated enamel matrix proteins may play a role as mineralization inhibitors. More recently, it has been reported that TNAP is expressed by normal ameloblasts in a stage-specific manner, that is, at the point of transition from secretory to maturation stage (Yadav et al., 2012). In addition, AP was found to be highly expressed by the adjacent stratum intermedium of the developing enamel organ. Importantly, this latter study also showed that the TNAP knockout mice not only exhibited a phenotype similar to infantile hypophosphatasia, but also marked enamel defects, including reduced mineralization and disrupted rod and interrod structures. Hence, the reversal of mineralization inhibition, by $\mathrm{PP}_{\mathrm{i}}$ hydrolysis or dephosphorylation, may represent a critical regulatory step in the formation of both developing bones and teeth.

Upon mineral growth, macromolecules found in bones and teeth can also effectively influence the morphology of calcium phosphate minerals through adsorption to specific crystal planes (e.g., Furedi-Milhofer et al., 1994; Flade et al., 2001). Of particular interest are observations that amelogenin (Iijima et al., 2001, 2002; Beniash et al., 2005), as well as other relevant biomineralization molecules like phosphophoryn (Burke et al., 2000) and glucose (Walsh et al., 1993), preferentially adsorb on (100), (010) faces of HA or OCP, suppressing their growth in a- and b-axis directions. Consequently, under these conditions, such crystals grow preferably along the long c-axis forming ribbon or needlelike structures resembling enamel crystals. As described in the next section, current evidence suggests that native amelogenins have the capacity to stabilize ACP, prevent unwanted crystallization, and ultimately guide the formation and organization of bundles of aligned enamel crystals during the secretory stage of enamel formation. The authors hypothesize, however, that the transformation of ACP to HA and the subsequent growth of HA crystals in thickness and width during maturation are the result of active regulation processes.

\section{MECHANISM OF DENTAL ENAMEL FORMATION}

Studies from our laboratory suggest that amelogenin mediates mineralization through a cooperative mechanism where mineralization and protein self-assembly occur simultaneously (Beniash et al., 2005). This conclusion is based on in vitro findings that show that the non-phosphorylated full-length recombinant mouse amelogenin, rM179, can guide the formation of well-aligned bundles of HA crystals in vitro, under experimental conditions designed to simultaneously induce amelogenin assembly and mineralization. Organized mineral formation was not observed when protein self-assembly was carried out prior to mineralization or when a truncated recombinant mouse amelogenin (rM166, lacking the hydrophilic C-terminus) was used. Similar results were subsequently obtained under cooperative assembly/mineralization conditions using recombinant fulllength porcine amelogenin, $\mathrm{rP} 172$, which was also found to guide the formation of bundles of aligned HA crystals (Kwak et al., 2009). These latter experiments were monitored as a function of time to provide insight into the mechanism of amelogeninmediated mineralization. These studies revealed that $\mathrm{rP} 172$ transiently stabilizes ACP nanoparticles (Figure 6), which were found to be significantly smaller than those seen in the control (Figure 3). As the reaction continued in the presence of rP172, an alignment of ACP nanoparticles was observed at $\sim 45 \mathrm{~min}$. Arrays of needle-like crystals were then observed between 1-4 h. At $24 \mathrm{~h}$, as shown, multiple bundles of well-aligned needle-like apatite crystals were seen that are similar to those found in the presence of rM179 (Beniash et al., 2005) and distinctly different 

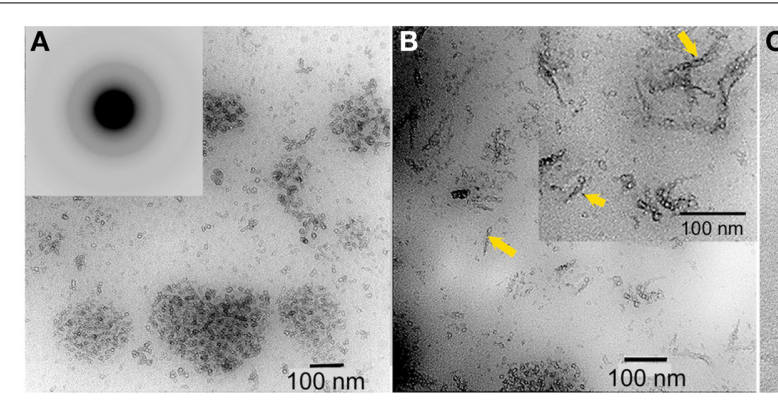

c

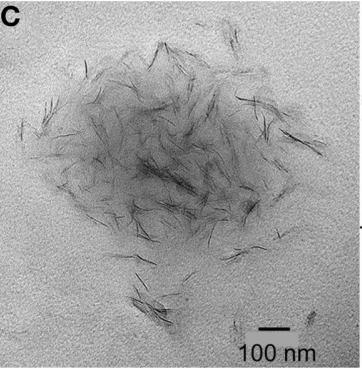

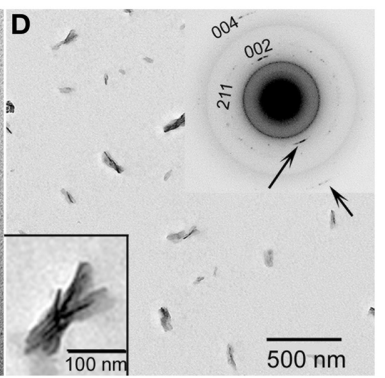

FIGURE 6 | TEM micrographs of calcium phosphate mineral products formed in the presence of $2 \mathrm{mg} / \mathrm{ml}$ recombinant full-length amelogenin, rP172, examined at selected times: $15 \mathrm{~min}(\mathrm{~A}), \mathbf{4 5} \mathrm{min}(B)$, 1-4h (C), and $\mathbf{1}$ d (D). ACP particles seen at $15 \mathrm{~min}$ (A, inset) were found to align to form need-like particles (arrows) at $45 \mathrm{~min}$ (B). After $1 \mathrm{~d}$, based on selected area electron diffraction analyzes (D, inset), aligned bundles of needle-like apatitic crystals were formed. This image was reproduced from Kwak et al. (2009). in comparison to the randomly arranged plate-like crystals found in the control (at $24 \mathrm{~h}$, Figure 3). Truncated recombinant (nonphosphorylated) porcine amelogenin $\mathrm{rP} 147$ had relatively little effect on the mineralization process (Kwak et al., 2009), again indicating that the full-length amelogenin has a unique capacity to guide ordered mineralization. This unique capacity is attributed to the fact that full-length recombinant mouse (rM179) and porcine (rP172) amelogenin, as well as full-length native amelogenin (P173), undergo self-assembly to form hierarchical nanosphere (Fang et al., 2011, 2013) and chain-like (Wiedemann-Bidlack et al., 2007, 2011) structures, as a function of solution $\mathrm{pH}$. Truncated amelogenins lacking the hydrophilic C-terminus do not form such organized structures. Notably, the single phosphate group in native amelogenins on serine-16 was found to have only a subtle influence on P173 assembly and structure, as determined by both conventional (WiedemannBidlack et al., 2011) and cryo-TEM (Fang et al., 2013). However, small-angle X-ray scattering studies using phosphorylated and non-phosphorylated leucine-rich amelogenin peptides (LRAP, an alternative splice product that is comprised of the first 33 amino acids and the last $23 \mathrm{C}$-terminal amino acids of full-length (porcine) amelogenin) showed that phosphorylation of serine-16 had a significant effect on the folding of the peptide in solution (Le Norcy et al., 2011a). LRAP(+P) exhibited an unfolded structure, while LRAP(-P) exhibited a globular structure in solution. $\operatorname{LRAP}(+\mathrm{P})$, like P173, was also found to effectively stabilize ACP and inhibit HA formation in vitro (Le Norcy et al., 2011b). These influences on protein structure and folding may be of considerable functional importance, given the marked effect phosphorylation has on the capacity of native amelogenins to stabilize ACP and inhibit HA formation for extended periods of time, as further discussed below.

In recent years, two prominent theories of crystal growthaptly named the classical and non-classical crystal growth theories, have received considerable attention, in part, through detailed investigations into the growth mechanisms of biominerals (Niederberger and Colfen, 2006). The classical mechanism for crystal growth is mineral ion mediated where mineral growth progresses through the successive accumulation of mineral ions to form a single crystal. The non-classical mechanism for crystal growth is mediated by initially formed nano-particles that subsequently assemble in an organized fashion to form what appear to be single crystals (so-called mesocrystals). Although it is often difficult to distinguish between these two mechanisms, early studies (Robinson et al., 1981; Robinson, 2007) have suggested that, during amelogenesis, enamel crystals form through the assembly of small amorphous mineral particles, although the amorphous nature of these particles was not verified experimentally. Since this initial proposal, however, data have been obtained that support the presence of ACP in the developing enamel matrix (Diekwisch, 1998; Bodier-Houlle et al., 2000). In a more recent study (Beniash et al., 2009), multiple independent techniques were used to carefully characterize the phase of the long thin parallel arrays of mineral deposits (e.g., as seen in Figure 7) that form during the secretory stage of amelogenesis that begin near the DEJ and extend to the enamel surface. Newly deposited mouse enamel, that is, in the outer enamel layers closer to the enamel surface and the ameloblast layer was found to be ACP, while older enamel, found in inner layers of enamel closer to DEJ contained apatitic crystals. Of particular importance, the newly deposited amorphous mineral and the older crystalline deposits had the same ribbon-like shape and organization in parallel arrays. These findings suggest that enamel mineral morphology and organization are established by the enamel matrix prior to the transformation of ACP to HA-like enamel crystals. These findings are also consistent with a proposed hypothesis that initial enamel crystals form from the assembly and fusion of amorphous calcium phosphate particles (e.g., Robinson, 2007). Transient amorphous mineral phases (i.e., ACP and amorphous calcium carbonate) have also been observed to be associated with a number of other biomineralization systems (Lowenstam and Weiner, 1985, 1989; Beniash et al., 1997; Wu et al., 1997; LeviKalisman et al., 2000; Aizenberg et al., 2002), including bone (Kim et al., 2005; Crane et al., 2006; Mahamid et al., 2008), leading to the proposal that the transformation of amorphous phases to crystalline materials is an important aspect of biological mineralization (Beniash et al., 1997; Weiner et al., 2005). Other molecules believed to be associated with the regulation of biomineralization, like highly phosphorylated osteopontin from milk (Gericke et al., 2005) and the N-terminal domain of dentin matrix protein 1 (Gajjeraman et al., 2007) have been shown to stabilize ACP. 


\section{POTENTIAL ROLE OF MINERALIZATION INHIBITORS IN DENTAL ENAMEL FORMATION}

Based on current evidence, inhibition of mineralization by native amelogenins and its reversal in vivo may play critical roles in enamel formation. This conclusion is supported by data showing (1) an inverse relationship between protein and mineral content (Figure 1), and the notably high protein and low mineral content (10-20\% by volume) of secretory stage enamel; (2) the capacity of native amelogenins to stabilize ACP and inhibit mineralization in vitro; (3) the apparent requirement for both proteases [i.e., matrix metalloproteinase 20 (MMP20) during the secretory stage Caterina et al., 2002 and kallikrein 4 (Klk4) during transition/maturation Hu et al., 2000; Simmer et al., 2009] and phosphatases (i.e., AP, as discussed above) for proper enamel formation; and (4) the rapid onset of mineral growth coinciding with loss of protein (Figure 1). These collective data suggest that during the secretory stage of enamel formation, enamel matrix proteins selectively guide ACP nanoparticle organization and transformation to thin ribbons of co-aligned HA crystals, while at the same time preventing unwanted bulk mineralization. Support for this scenario was recently provided by in vitro findings showing that under the proper kinetic conditions, controlled by variations in protein concentration, significantly lower concentrations of P173 can guide the transformation of initially stabilized ACP nanoparticles to ordered bundles of HA crystals that have similar morphology to initially formed enamel crystals (Kwak et al., 2014). In contrast to that seen with P173, however, P148 lacked the capacity to regulate ordered mineralization at reduced protein concentrations, although mineralization did take place. At higher concentrations, again, both P173 and P148 are potent stabilizers of ACP. Hence, upon its secretion, the parent phosphorylated full-length amelogenin P173 can initially prevent

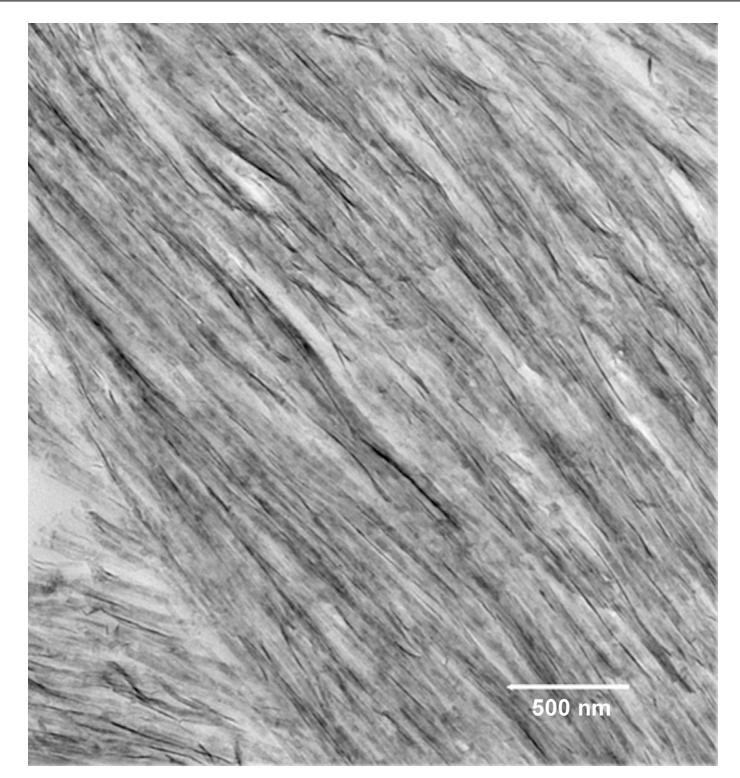

FIGURE 7 | Transmission electron microscopy micrograph of secretory stage mouse enamel showing parallel arrays of long thin ribbons of mineral. premature mineralization of HA crystals in forming enamel. However, full-length amelogenin undergoes proteolytic processing soon after secretion, resulting in a significant decrease in its concentration. In developing porcine enamel, the P173 content of secretory enamel was found to be only $7.4 \%$ of total amelogenin, a reduction in P173 by more than 90\% (Wen et al., 1999). P173 was also found to be exclusively associated with newly formed enamel mineral (Uchida et al., 1991). In contrast to P173, the P148 content of the enamel matrix increases and becomes the predominant amelogenin cleavage product at $49.5 \%$ of total amelogenin (Wen et al., 1999). Based on these combined in vitro and in vivo findings, the authors propose that the onset of enamel crystal formation is regulated by a marked reduction ( $>10$-fold) in P173 concentration to attain a critical lower level that has the potential to organize forming mineral deposits into oriented bundles of elongated HA crystals, as illustrated in a proposed model presented in Figure 8. At the same time, substantially higher concentrations of $\mathrm{P} 148(\sim 6-7$ times higher than P173) that accumulate in the developing (porcine) enamel matrix serve an important role by preventing uncontrolled mineralization throughout the secretory stage of amelogenesis where the mineral volume is only 10-20\% (Robinson et al., 1988; Fukae, 2002).

The noted proteolytic processing of amelogenin during the secretory stage of amelogenesis has been primarily attributed to MMP20 that is exclusively expressed during this initial stage of enamel formation. MMP20 has also been shown to be essential for proper enamel formation (Caterina et al., 2002). In its absence, the enamel layer is about one-half the normal thickness

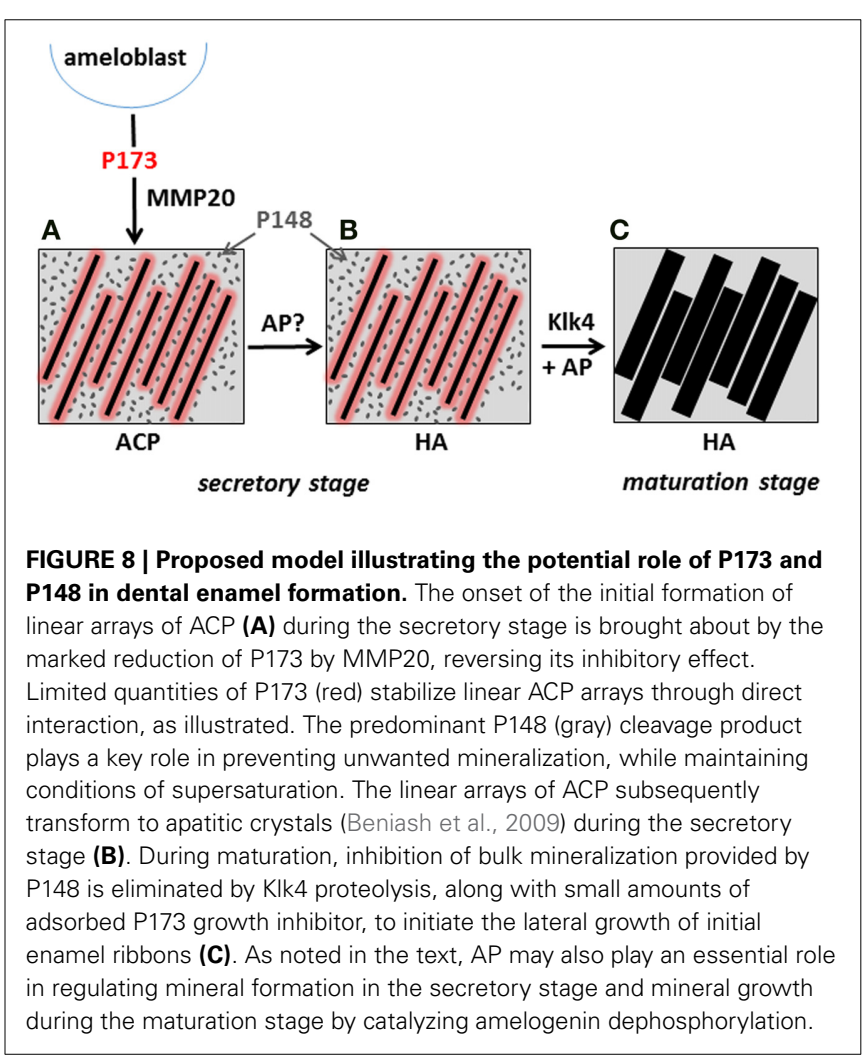


and the decussating prism pattern of normal enamel is substantially disrupted. These latter findings verify that proteolytic processing of full-length amelogenin is required for proper enamel formation, consistent with our proposed model, that is based on the capacity of reduced levels of P173 to guide ordered HA crystal formation, while accumulating P148 levels maintain mineralization driving forces by preventing unwanted bulk mineralization. During maturation, Klk4 is predominantly expressed and is believed to be responsible for removing almost all of the remaining enamel matrix to allow the initial enamel crystals to grow in width and thickness (Hu et al., 2000). Hence, as illustrated in the presented model, we propose that the onset of mineralization during the secretory stage is brought about by the marked reduction of P173 content by MMP20, reversing its inhibitory effect. During maturation, inhibition of bulk mineralization provided by P148 is eliminated by Klk4 proteolysis, along with small amounts of adsorbed P173 growth inhibitor, to initiate the lateral growth of the secretory stage enamel ribbons. As noted above, AP may also play an essential role in regulating mineral formation in the secretory stage and mineral growth during the maturation stage by catalyzing amelogenin dephosphorylation and removing the noted mineralization inhibitory activity found to be associated with native amelogenins. The timing of the expression of key regulators of biomineralization during enamel formation is, therefore, of critical importance (e.g., Smith, 1998; Simmer et al., 2009). Additional studies addressing the potential roles of amelogenin proteolysis and de-phosphorylation in regulating initial enamel mineral formation and maturation are currently underway in our laboratory.

\section{CONCLUSIONS}

Mineralization inhibitors can play critical roles in regulating mineralized tissue formation, stability, and regeneration in vivo. With respect to dental enamel formation, mineralization events triggered by the proteolysis and/or de-phosphorylation of full-length native amelogenin during the secretory stage of amelogenesis may play an essential role in regulating enamel mineral formation and its hierarchical structure, while predominant amelogenin degradation products, like P148, serve to prevent uncontrolled mineral formation. During maturation, residual inhibition is removed via additional matrix processing, allowing initial enamel crystals to expand to form the highly dense enamel mineral layer.

\section{ACKNOWLEDGMENT}

This work is supported by NIDCR grant R01-DE023091 (Henry C. Margolis).

\section{REFERENCES}

Addadi, L., and Weiner, S. (1992). Control and design principles in biological mineralization. Angew. Chem. Int. Ed. 31, 153-169. doi: 10.1002/anie.199201531

Aizenberg, J., Lambert, G., Weiner, S., and Addadi, L. (2002). Factors involved in the formation of amorphous and crystalline calcium carbonate: a study of an ascidian skeleton. J. Am. Chem. Soc. 124, 32-39. doi: 10.1021/ja0169901

Arsenault, A. L., and Robinson, B. W. (1989). The Dentino-enamel junction: a structural and microanalytical study of early mineralization. Calcif. Tissue Int. 45, 111-121. doi: 10.1007/BF02561410

Beniash, E., Aizenberg, J., Addadi, L., and Weiner, S. (1997). Amorphous calcium carbonate transforms into calcite during sea urchin larval spicule growth. Proc Biol Sci. 264, 461-465.
Beniash, E., Metzler, R. A., Lam, R. S. K., and Gilbert, P. (2009). Transient amorphous calcium phosphate in forming enamel. J. Struct. Biol. 167, 95-95. doi: 10.1016/j.jsb.2009.04.002

Beniash, E., Simmer, J. P., and Margolis, H. C. (2005). The effect of recombinant mouse amelogenins on the formation and organization of hydroxyapatite crystals in vitro. J. Struct. Biol. 149, 182-190. doi: 10.1016/j.jsb.2004.11.001

Beniash, E., Traub, W., Veis, A., and Weiner, S. (2000). A transmission electron microscope study using vitrified ice sections of predentin: structural changes in the dentin collagenous matrix prior to mineralization. J. Struct. Biol. 132, 212-225. doi: 10.1006/jsbi.2000.4320

Birchall, J. D. (1989). "The importance of the study of biominerals to materials technology," in Biomineralization: Chemical and Biochemical Perspectives. In Book the Importance of the Study of Biominerals to Materials Technology. In: Biomineralization: Chemical and Biochemical Perspectives, eds S. Mann, J. Webb, and R. J. P. Williams (New York, NY: VCH Publishers), 491-509.

Blumenthal, N. C., Betts, F., and Posner, A. S. (1975). Nucleoside stabilization of amorphous calcium phosphate. Mater. Res. Bull. 10, 1055-1060. doi: 10.1016/0025-5408(75)90214-7

Bodier-Houlle, P., Steuer, P., Meyer, J. M., Bigeard, L., and Cuisinier, F. J. (2000). High-resolution electron-microscopic study of the relationship between human enamel and dentin crystals at the dentinoenamel junction. Cell Tissue Res. 301, 389-395. doi: 10.1007/s004410000241

Boskey, A. L. (1997). Amorphous calcium phosphate: the contention of bone. J. Dent. Res. 76, 1433-1436. doi: 10.1177/00220345970760080501

Brookes, S. J., Kirkham, J., Shore, R. C., Bonass, W. A., and Robinson, C. (1998). Enzyme compartmentalization during biphasic enamel matrix processing. Connect. Tissue Res. 39, 89-99. doi: 10.3109/03008209809023915

Burke, E. M., Guo, Y., Colon, L., Rahima, M., Veis, A., and Nancollas, G. H. (2000). Influence of polyaspartic acid and phosphophoryn on octacalcium phosphate growth kinetics. Colloids Surf. B. Biointerfaces 17, 49-57. doi: 10.1016/S09277765(99)00084-3

Caterina, J. J., Skobe, Z., Shi, J., Ding, Y. L., Simmer, J. P., Birkedal-Hansen, H., et al. (2002). Enamelysin (matrix metalloproteinase 20)-deficient mice display an amelogenesis imperfecta phenotype. J. Biol. Chem. 277, 49598-49604. doi: 10.1074/jbc.M209100200

Colfen, H., and Mann, S. (2003). Higher-order organization by mesoscale selfassembly and transformation of hybrid nanostructures. Angew. Chem. Int. Ed Engl. 42, 2350-2365. doi: 10.1002/anie.200200562

Crane, N. J., Popescu, V., Morris, M. D., Steenhuis, P., and Ignelzi, M. A. Jr. (2006). Raman spectroscopic evidence for octacalcium phosphate and other transient mineral species deposited during intramembranous mineralization. Bone 39, 434-442. doi: 10.1016/j.bone.2006.02.059

Currey, J. D. (1999). The design of mineralised hard tissues for their mechanical functions. J. Exp. Biol. 202, 3285-3294.

Deshpande, A. S., and Beniash, E. (2008). Bioinspired synthesis of mineralized collagen fibrils. Cryst. Growth Des. 8, 3084-3090. doi: 10.1021/cg800252f

Diekwisch, T. G. (1998). Subunit compartments of secretory stage enamel matrix. Connect. Tissue Res. 38, 101-111. discussion: 139-145. doi: 10.3109/03008209809017026

Dirks, O. B. (1966). Posteruptive changes in dental enamel. J. Dent. Res. 45, 503-510. doi: 10.1177/00220345660450031101

Eanes, E. D. (2001). "Amorphous calcium phosphate: in octacalcium phosphate; Monographs in oral science," in Book Amorphous Calcium Phosphate: In Octacalcium Phosphate; Monographs in Oral Science, eds L. C. Chow and E. D. Eanes (Basel: Karger), 130-147.

Fang, P. A., Conway, J. F., Margolis, H. C., Simmer, J. P., and Beniash, E. (2011). Hierarchical self-assembly of amelogenin and the regulation of biomineralization at the nanoscale. Proc. Natl. Acad. Sci. U.S.A. 108, 14097-14102. doi: 10.1073/pnas.1106228108

Fang, P. A., Margolis, H. C., Conway, J. F., Simmer, J. P., and Beniash, E. (2013). CryoTEM study of effects of phosphorylation on the hierarchical assembly of porcine amelogenin and its regulation of mineralization in vitro. J. Struct. Biol. 183, 250-257. doi: 10.1016/j.jsb.2013.05.011

Flade, K., Lau, C., Mertig, M., and Pompe, W. (2001). Osteocalcin-controlled dissolution-reprecipitation of calcium phosphate under biomimetic conditions. Chem. Mater. 13, 3596-3602. doi: 10.1021/cm011063z

Fleisch, H., Maerki, J., and Russell, R. G. G. (1966). Effect of pyrophosphate on dissolution of hydroxyapatite and its possible importance in calcium homeostasis Proc. Soc. Exp. Biol. Med. 122, 317-320. doi: 10.3181/00379727-122-31123 
Francis, M. D. (1969). Inhibition of calcium hydroxyapatite crystal growth by polyphosphonates and polyphosphates. Calcif. Tissue Res. 3, 151-162. doi: 10.1007/BF02058658

Fukae, M. (2002). "Amelogenesis- three-dimensional structure of amelogenin micelles and their degradation by a cascade system," in The Proceedings of International Symposium of Oral Science in Tsurumi University School of Dental Medicine (Tsurumi).

Fukumoto, S., Kiba, T., Hall, B., Iehara, N., Nakamura, T., Longenecker, G., et al. (2004). Ameloblastin is a cell adhesion molecule required for maintaining the differentiation state of ameloblasts. J. Cell Biol. 167, 973-983. doi: 10.1083/jcb.200409077

Furedi-Milhofer, H., Moradian-Oldak, J., Weiner, S., Veis, A., Mintz, K. P., and Addadi, L. (1994). Interactions of matrix proteins from mineralized tissues with octacalcium phosphate. Connect. Tissue Res. 30, 251-264. doi: 10.3109/ 03008209409015041

Gajjeraman, S., Narayanan, K., Hao, J. J., Qin, C. L., and George, A. (2007). Matrix macromolecules in hard tissues control the nucleation and hierarchical assembly of hydroxyapatite. J. Biol. Chem. 282, 1193-1204. doi: 10.1074/jbc. M604732200

Gericke, A., Qin, C., Spevak, L., Fujimoto, Y., Butler, W. T., Sorensen, E. S., et al. (2005). Importance of phosphorylation for osteopontin regulation of biomineralization. Calcif. Tissue Int. 77, 45-54. doi: 10.1007/s00223-004-1288-1

Gibson, C. W., Yuan, Z. A., Hall, B., Longenecker, G., Chen, E. H., Thyagarajan, T., et al. (2001). Amelogenin-deficient mice display an amelogenesis imperfecta phenotype. J. Biol. Chem. 276, 31871-31875. doi: 10.1074/jbc.M104624200

Habraken, W., Tao, J. H., Brylka, L. J., Friedrich, H., Bertinetti, L., Schenk, A. S., et al. (2013). Ion-association complexes unite classical and non-classical theories for the biomimetic nucleation of calcium phosphate. Nature 4, 12. doi: $10.1038 /$ ncomms 2490

Hay, D. I., Moreno, E. C., and Schlesinger, D. H. (1979). Phosphoprotein inhibitor of calcium phosphate precipitation from human salivary secrections. Inorg. Perspect. Biol. Med. 2, 271-285.

Hay, D. I., Schluckebier, S. K., and Moreno, E. C. (1982). Equilibrium dialysis and ultrafiltration studies of calcium and phosphate binding by human salivary proteins. Implications for salivary supersaturation with respect to calcium phosphate salts.Calcif. Tissue Int. 34, 531-538. doi: 10.1007/BF02411299

He, G., Ramachandran, A., Dahl, T., George, S., Schultz, D., Cookson, D., et al. (2005). Phosphorylation of phosphophoryn is crucial for its function as a mediator of biomineralization. J. Biol. Chem. 280, 33109-33114. doi: 10.1074/jbc.M500159200

Hessle, L., Johnson, K. A., Anderson, H. C., Narisawa, S., Sali, A., Goding, J. W., et al. (2002). Tissue-nonspecific alkaline phosphatase and plasma cell membrane glycoprotein-1 are central antagonistic regulators of bone mineralization. Proc. Natl. Acad. Sci. U.S.A. 99, 9445-9449. doi: 10.1073/pnas.142063399

Ho, A. M., Johnson, M. D., and Kingsley, D. M. (2000). Role of the mouse ank gene in control of tissue calcification and arthritis. Science 289, 265-270. doi: 10.1126/science.289.5477.265

Hu, J. C. C., Hu, Y. Y., Smith, C. E., McKee, M. D., Wright, J. T., Yamakoshi, Y., et al. (2008). Enamel defects and ameloblast-specific expression in Enam knock-out/lacZ knock-in mice. J. Biol. Chem. 283, 10858-10871. doi: 10.1074/jbc.M710565200

Hu, J. C. C., Ryu, O. H., Chen, J. J., Uchida, T., Wakida, K., Murakami, C., et al. (2000). Localization of EMSP1 expression during tooth formation and cloning of mouse cDNA. J. Dent. Res. 79, 70-76. doi: 10.1177/00220345000790011301

Iijima, M., Moriwaki, Y., Takagi, T., and Moradian-Oldak, J. (2001). Effects of bovine amelogenins on the crystal morphology of octacalcium phosphate in a model system of tooth enamel formation. J. Cryst. Growth 222, 615-626. doi: 10.1016/S0022-0248(00)00984-2

Iijima, M., Moriwaki, Y., Wen, H. B., Fincham, A. G., and Moradian-Oldak, J. (2002). Elongated growth of octacalcium phosphate crystals in recombinant amelogenin gels under controlled ionic flow. J. Dent. Res. 81, 69-73. doi: $10.1177 / 154405910208100115$

Kim, H. M., Himeno, T., Kokubo, T., and Nakamura, T. (2005). Process and kinetics of bonelike apatite formation on sintered hydroxyapatite in a simulated body fluid. Biomaterials 26, 4366-4373. doi: 10.1016/j.biomaterials.2004. 11.022

Koulourides, T., Feagin, F., and Pigman, W. (1965). Remineralization of dental enamel by saliva in vitro. Ann. N. Y. Acad. Sci. 131, 751-757. doi: 10.1111/j.17496632.1965.tb34839.x
Kwak, S. Y., Kim, S., Yamakoshi, Y., Simmer, J. P., Beniash, E., and Margolis, H. C. (2014). Regulation of calcium phosphate formation by native amelogenins in vitro. Connect. Tissue Res. 55(S1), 21-24. doi: 10.3109/03008207.2014.923853

Kwak, S. Y., Wiedemann-Bidlack, F. B., Beniash, E., Yamakoshi, Y., Simmer, J. P., Litman, A., et al. (2009). Role of 20-kDa Amelogenin (P148) phosphorylation in calcium phosphate formation in vitro. J. Biol. Chem. 284, 18972-18979. doi: 10.1074/jbc.M109.020370

Le Norcy, E., Kwak, S. Y., Allaire, M., Fratzl, P., Yamakoshi, Y., Simmer, J. P., et al. (2011a). Effect of phosphorylation on the interaction of calcium with leucinerich amelogenin peptide. Eur. J. Oral Sci. 119, 97-102. doi: 10.1111/j.16000722.2011.00900.x

Le Norcy, E., Kwak, S. Y., Wiedemann-Bidlack, F. B., Beniash, E., Yamakoshi, Y., Simmer, J. P., et al. (2011b). Leucine-rich amelogenin peptides regulate mineralization in vitro. J. Dent. Res. 90, 1091-1097. doi: 10.1177/0022034511411301

Levi-Kalisman, Y., Raz, S., Weiner, S., Addadi, L., and Sagi, I. (2000). X-Ray absorption spectroscopy studies on the structure of a biogenic amorphous calcium carbonate phase. J. Chem. Soc. Dalton Trans. 21, 3977-3982. doi: 10.1039/b003242p

Lowenstam, H. A., and Weiner, S. (1989). On Biomineralization. New York, NY: Oxford University Press.

Lowenstam, H. A., and Weiner, S. (1985). Transformation of amorphous calcium phosphate to crystalline dahllite in the radular teeth of chitons. Science 227, 51-53. doi: 10.1126/science.227.4682.51

Luo, G. B., Ducy, P., McKee, M. D., Pinero, G. J., Loyer, E., Behringer, R. R., et al. (1997). Spontaneous calcification of arteries and cartilage in mice lacking matrix GLA protein. Nature 386, 78-81. doi: 10.1038/386078a0

Mahamid, J., Sharir, A., Addadi, L., and Weiner, S. (2008). Amorphous calcium phosphate is a major component of the forming fin bones of zebrafish: indications for an amorphous precursor phase. Proc. Natl. Acad. Sci. U.S.A. 105, 12748-12753. doi: 10.1073/pnas.0803354105

Mann, S. (2001). "Chemical control of biomineralization," in Biomineralization: Principles and Concepts in Bioinorganic Materials Chemistry, ed S. Mann (Oxford: Oxford University Press), 58-62.

Margolis, H. C., and Beniash, E. (2010). "The role of amelogenin in dental enamel formation: a universal strategy for protein-mediated biomineralization," in Amelogenins: Multifaceted Proteins for Dental and Bone Formation and Repair, ed M. Goldberg (Bentham Science Publishers), 133-142.

Margolis, H. C., Beniash, E., and Fowler, C. E. (2006). Role of macromolecular assembly of enamel matrix proteins in enamel formation. J. Dent. Res. 85, 775-793. doi: 10.1177/154405910608500902

McGaughey, C. (1983). Binding of polyphosphates and phosphonates to hydroxyapatite, subsequent hydrolysis, phosphate exchange and effects on demineralization, mineralization and microcrystal aggregation Caries Res. 17, 229-241. doi: $10.1159 / 000260671$

McGaughey, C., and Stowell, E. C. (1977). Effects of polyphosphates on the solubility and mineralization of HA: relevance to a rationale for anticaries activity. J. Dent. Res. 56, 579-587. doi: 10.1177/00220345770560060501

Meyer, J. L. (1984). Can biological calcification occur in the presence of pyrophosphate?. Arch. Biochem. Biophys. 231, 1-8. doi: 10.1016/0003-9861(84)90356-4

Meyer, J. L., and Eanes, E. D. (1978). Thermodynamic analysis of the amorphous to crystalline calcium phosphate transformation. Calcif. Tissue Res. 25, 59-68. doi: 10.1007/BF02010752

Meyer, J. L., and Nancollas, G. H. (1973). Influence of multidentate organic phosphonates on the crystal growth of hydroxyapatite. Calcif. Tissue Res. 13, 295-303. doi: 10.1007/BF02015419

Meyer, J. L., and Reddi, A. H. (1985). Changes in pyrophosphatase activity during the de novo mineralization associated with cartilage and bone formation. Arch. Biochem. Biophys. 242, 532-539. doi: 10.1016/0003-9861(85)90240-1

Moreno, E. C., Aoba, T., and Margolis, H. C. (1987). Pyrophosphate adsorption onto hydroxyapatite and its inhibition of crystal growth. Compend. Suppl. 8, S256-S266.

Moreno, E. C., and Margolis, H. C. (1988). Composition of human plaque fluids. J. Dent. Res. 67, 1181-1189. doi: 10.1177/00220345880670090701

Moreno, E. C., Varughese, K., and Hay, D. I. (1979). Effect of human salivary proteins on the precipitation kinetics of calcium phosphate. Calcif. Tissue Int. 28, 7-16. doi: 10.1007/BF02441212

Nene, S. S., Hunter, G. K., Goldberg, H. A., and Hutter, J. L. (2013). Reversible inhibition of calcium oxalate monohydrate growth by an osteopontin phosphopeptide. Langmuir 29, 6287-6295. doi: 10.1021/la400891b 
Niederberger, M., and Colfen, H. (2006). Oriented attachment and mesocrystals: non-classical crystallization mechanisms based on nanoparticle assembly. Phys. Chem. Chem. Phys. 8, 3271-3287. doi: 10.1039/b604589h

Nikiforuk, G. (ed.). (1985). In Understanding Dental Caries. 1. Etiology and Mechanisms Basic and Clinical Aspects. Basel: Karger, 13-141.

Nylen, M. U., Omnell, K. A., and Eanes, E. D. (1963). Crystal growth in rat enamel. J. Cell Biol. 18, 109-123. doi: 10.1083/jcb.18.1.109

Ofir, P. B. Y., Govrin-Lippman, R., Garti, N., and Furedi-Milhofer, H. (2004). The influence of polyelectrolytes on the formation and phase transformation of amorphous calcium phosphate. Cryst. Growth Des. 4, 177-183. doi: $10.1021 / \operatorname{cg} 034148 \mathrm{~g}$

Posner, A. S., and Betts, F. (1975). Synthetic amorphous calcium phosphate and its relation to bone mineral structure. Acc. Chem. Res. 8, 273-281. doi: $10.1021 / \operatorname{ar} 50092 \mathrm{a} 003$

Robertson, W. G. (1973). Factors affecting the precipitation of calcium phosphate in vitro Calcif. Tissue Res. 11, 311-322. doi: 10.1007/BF02547230

Robinson, C. (2007). Self-oriented assembly of nano-apatite particles: a subunit mechanism for building biological mineral crystals. J. Dent. Res. 86, 677-679. doi: $10.1177 / 154405910708600801$

Robinson, C., Briggs, H. D., Atkinson, P. J., and Weatherell, J. A. (1979). Matrix and mineral changes in developing enamel. J. Dent. Res. 58, 871-882. doi: 10.1177/00220345790580024101

Robinson, C., Fuchs, P., and Weatherell, J. A. (1981). The appearance of developing rat incisor enamel using a freeze fracturing technique. J. Cryst. Growth. 53, 160-165. doi: 10.1016/0022-0248(81)90062-2

Robinson, C., and Kirkham, J. (1985). "The dynamics of amelogenesis as revealed by protein compositional studies," in The Chemistry and Biology of Mineralized Tissues. In Book The Dynamics of Amelogenesis as Revealed by Protein Compositional Studies. In: The Chemistry and Biology of Mineralized Tissues, ed W. T. Butler (Birmingham, AL: Ebsco Media Inc.), 248-263.

Robinson, C., Kirkham, J., and Hallsworth, A. S. (1988). Volume distribution and concentration of protein, mineral and water in developing bovine enamel. Arch. Oral Biol. 33, 159-162. doi: 10.1016/0003-9969(88)90040-4

Schroeder, H. E. (ed.). (1969). Formation and Inhibition of Dental Calculus. Berne: Verlag Hans Huber, 119-122.

Septier, D., Hall, R. C., Lloyd, D., Embery, G., and Goldberg, M. (1998). Quantitative immunohistochemical evidence of a functional gradient of chondroitin 4-sulphate dermatan sulphate, developmentally regulated in the predentine of rat incisor. Histochem. J. 30, 275-284. doi: 10.1023/A:100321 6024158

Simmer, J. P., Hu, Y. Y., Lertlam, R., Yamakoshi, Y., and Hu, J. C. C. (2009). Hypomaturation enamel defects in Klk4 knockout/LacZ knockin mice. J. Biol. Chem. 284, 19110-19121. doi: 10.1074/jbc.M109.013623

Smith, C. E. (1998). Cellular and chemical events during enamel maturation. Crit. Rev. Oral Biol. Med. 9, 128-161. doi: 10.1177/10454411980090020101

Smith, C. E., Wazen, R., Hu, Y. Y., Zalzal, S. F., Nanci, A., Simmer, J. P., et al. (2009). Consequences for enamel development and mineralization resulting from loss of function of ameloblastin or enamelin. Eur. J. Oral Sci. 117, 485-497. doi: 10.1111/j.1600-0722.2009.00666.x

Termine, J. D., and Posner, A. S. (1966). Infrared analysis of rat bone-age dependency of amorphous and crystalline mineral fractions. Science 153, 1523-1525. doi: 10.1126/science.153.3743.1523

Termine, J. D., Peckausk, R. A., and Posner, A. S. (1970). Calcium phosphate formation in vitro. II. Effects of environment on amorphous-crystalline transformation.Arch. Biochem. Biophys. 140, 318-325. doi: 10.1016/0003-9861(70) 90072-X

Torres-Quintana, M. A., Lecolle, S., Septier, D., Palmier, B., Rani, S., MacDougall, M., et al. (2000). Inositol hexasulphate, a casein kinase inhibitor, alters enamel formation in cultured embryonic in embryonic mouse tooth germs. J. Dent. Res. 79, 1794-1801. doi: 10.1177/00220345000790101101
Uchida, T., Tanabe, T., Fukae, M., Shimizu, M., Yamada, M., Miake, K., et al. (1991). Immunochemical and immunohistochemical studies, using antisera against porcine $25 \mathrm{kDa}$ amelogenin, $89 \mathrm{kDa}$ enamelin and the $13-17 \mathrm{kDa}$ nonamelogenins, on immature enamel of the pig and rat. Histochemistry 96, 129-138. doi: 10.1007/BF00315983

Veis, A., Sabsay, B., and Wu, C. B. (1991). Phosphoproteins as mediators of biomineralization. ACS Symp. Ser. 444, 1-12. doi: 10.1021/bk-1991-0444.ch001

Walsh, D., Kingston, J. L., Heywood, B. R., and Mann, S. (1993). Influence of monosaccharides and related molecules on the morphology of hydroxyapatite. J. Cryst. Growth 133, 1-12. doi: 10.1016/0022-0248(93)90097-G

Wazen, R. M., Moffatt, P., Zalzal, S. F., Yamada, Y., and Nanci, A. (2009). A mouse model expressing a truncated form of ameloblastin exhibits dental and junctional epithelium defects. Matrix Biol. 28, 292-303. doi: 10.1016/j.matbio.2009.04.004

Weiner, S. (1986). Organization of extracellularly mineralized tissues: a comparative study of biological crystal growth. CRC Crit. Rev. Biochem. 20, 365-408. doi: $10.3109 / 10409238609081998$

Weiner, S. (2006). Transient precursor strategy in mineral formation of bone. Bone 39, 431-433. doi: 10.1016/j.bone.2006.02.058

Weiner, S., Sagi, I., and Addadi, L. (2005). Choosing the crystallization path less traveled. Science 309, 1027-1028. doi: 10.1126/science.1114920

Weinstock, M., and Leblond, C. P. (1973). Autoradiographic visualization of the deposition of a phosphoprotein at the mineralization front in the dentin of the rat incisor. J. Cell Biol. 56, 838-845. doi: 10.1083/jcb.56.3.838

Wen, H. B., Moradian-Oldak, J., Leung, W., Bringas, P., and Fincham, A. G. (1999). Microstructures of an amelogenin gel matrix. J. Struct. Biol. 126, 42-51. doi: 10.1006/jsbi.1999.4086

Wiedemann-Bidlack, F. B., Beniash, E., Yamakoshi, Y., Simmer, J. P., and Margolis, H. C. (2007). pH triggered self-assembly of native and recombinant amelogenins under physiological $\mathrm{pH}$ and temperature in vitro. J. Struct. Biol. 160, 57-69. doi: 10.1016/j.jsb.2007.06.007

Wiedemann-Bidlack, F. B., Kwak, S. Y., Beniash, E., Yamakoshi, Y., Simmer, J. P., and Margolis, H. C. (2011). Effects of phosphorylation on the self-assembly of native full-length porcine amelogenin and its regulation of calcium phosphate formation in vitro. J. Struct. Biol. 173, 250-260. doi: 10.1016/j.jsb.2010.11.006

Wu, L. N. Y., Genge, B. R., Dunkelberger, D. G., LeGeros, R. Z., Concannon, B., and Wuthier, R. E. (1997). Physicochemical characterization of the nucleational core of matrix vesicles. J. Biol. Chem. 272, 4404-4411. doi: 10.1074/jbc.272. 7.4404

Yadav, M. C., de Oliveira, R. C., Foster, B. L., Fong, H., Cory, E., Narisawa, S., et al. (2012). Enzyme replacement prevents enamel defects in hypophosphatasia mice. J. Bone Miner. Res. 27, 1722-1734. doi: 10.1002/jbmr.1619

Conflict of Interest Statement: The authors declare that the research was conducted in the absence of any commercial or financial relationships that could be construed as a potential conflict of interest.

Received: 15 July 2014; paper pending published: 11 August 2014; accepted: 19 August 2014; published online: 10 September 2014.

Citation: Margolis HC, Kwak S-Y and Yamazaki H (2014) Role of mineralization inhibitors in the regulation of hard tissue biomineralization: relevance to initial enamel formation and maturation. Front. Physiol. 5:339. doi: 10.3389/fphys.2014.00339

This article was submitted to Craniofacial Biology, a section of the journal Frontiers in Physiology.

Copyright (C) 2014 Margolis, Kwak and Yamazaki. This is an open-access article distributed under the terms of the Creative Commons Attribution License (CC BY). The use, distribution or reproduction in other forums is permitted, provided the original author(s) or licensor are credited and that the original publication in this journal is cited, in accordance with accepted academic practice. No use, distribution or reproduction is permitted which does not comply with these terms. 